\title{
Humanizar é Dar Voz: a Experiência de um Grupo de Apoio ao Adolescente com Câncer
}

\author{
Lima, Maria Juliana Vieira; Shioga, Julia Evangelista Mota; Silva, Emanuelly Mota; Maia, \\ Anice Holanda Nunes; Lage, Ana Maria Vieira \\ Universidade Federal do Ceará — mjulianavlima@hotmail.com
}

A adolescência é um período que traz mudanças a nível corporal e social. É o período em que surgem novas possibilidades e escolhas, mudanças hormonais e a descoberta de impulsos sexuais, sentimentos e novas vivencias em relacionamentos fora do contexto familiar. no entanto, mesmo a adolescência trazendo o sentimento do novo, o adolescente não está imune de um fator que pode desencadear mudanças irreversíveis: o câncer. Sendo assim, o tratamento pode modificar a autoestima e sua forma de lidar com o mundo, além de alterar a rotina e trazer mudanças de sonhos e investimentos. Pautando-se em uma estratégia de fortelecimento da autonomia dos usuários, em 2013 foi iniciado um grupo de apoio aos adolescentes com câncer, com a participação das equipes de Psicologia e Terapia Ocupacional de um centro hospitalar de tratamento oncológico infantojuvenil. o grupo era aberto e tinha caráter educativo e de apoio emocional. o objetivo do presente trabalho é relatar a experiência de atuação no grupo, levantando aspectos significativos à temática e explanando sobre os resultados iniciais dos encontros. a relevância do grupo se deu pela importância de um olhar diferenciado para o adolescente com câncer, reconhecendo que a doença não anula as particularidades dessa fase, observando se existem e quais são as mudanças significativas nesse processo de tratamento, além de prestar apoio ao adolescente com câncer, no que tange a suas demandas relacionadas ao adoecimento e hospitalização, bem como a demandas outras relacionadas ao seu modo próprio de ser e estar no mundo. o grupo de Apoio ao Adolescente com Câncer ocorria semanalmente, pelo período de duas horas no espaço do hospital destinado aos adolescentes, local de apropriação e identificação pelo público-alvo. a faixa etária de frequentadores variou de 11 a 17 anos e teve boa aceitação pelos profissionais, familiares e, principalmente, pelos pacientes. Foram realizados 11 encontros, com participação de, em média, 5 adolescentes por encontro; os temas eram escolhidos por eles e os mais discutidos foram sobre relações sociais: amizades, família, infância; questões de cunho social: regras, preconceito; e questões relativas à doença e ao tratamento. Utilizou-se dinâmicas, letras de músicas e outros recursos que possibilitaram a maior participação dos integrantes e tornaram os encontros mais interativos. Percebeu-se que o grupo promoveu cooperação entre os membros, além de propiciar um suporte acerca da hospitalização e do tratamento; formaram-se vínculos entre os participantes e os mesmos tornaram-se mais solícitos à equipe de saúde. a estratégia do grupo de apoio "deu voz" aos usuários que tornaram os encontros momentos de debate, trocas e vivências; auxiliando na adesão ao tratamento, fortalecendo a autonomia dos integrantes e possibilitando o protagonismo no processo saúde-doença.

Lima, Maria Juliana Vieira; Shioga, Julia Evangelista Mota; Silva, Emanuelly Mota; Maia, Anice Holanda Nunes; Lage, Ana Maria Vieira. Humanizar É Dar Voz: a Experiência de um Grupo de Apoio ao Adolescente com Câncer. In: Anais do Congresso Internacional de Humanidades \& Humanização em Saúde [= Blucher Medical Proceedings, num.2, vol.1]. São Paulo: Editora Blucher, 2014. ISSN 2357-7282

DOI 10.5151/medpro-cihhs-10611 